Journal of Korean Powder Metallurgy Institute

Vol. 16, No. 4, 2009

DOI: $10.4150 /$ KPMI.2009.16.4.249

\title{
$\mathrm{Fe}-\mathrm{Si} / \mathrm{Fe}$ 혼합분말의 온간성형 및 자성특성
}

\author{
김세훈 $\cdot$ 석명진 ${ }^{a} \cdot$ 김영도*
}

한양대학교 신소재공학과, ${ }^{a}$ 강원대학교 재료금속공학과

\section{Warm Compaction of Fe-Si/Fe Powder Mixture and its Magnetic Property}

\author{
Se Hoon Kim, Myung-Jin Suk ${ }^{a}$ and Young Do Kim* \\ Division of Materials Science and Engineering, Hanyang University, Seoul 133-791, Korea \\ ${ }^{a}$ Department of Materials \& Metallurgical Engineering, Kangwon National University, \\ Samcheok 245-711, Korea
}

(Received May 4, 2009; Revised May 26, 2009; Accepted June 4, 2009)

\begin{abstract}
D shape soft magnetic composite parts can be formed by general compaction method of powder metallurgy. In this study, the results on the high density nanostructured $\mathrm{Fe}-\mathrm{Si} / \mathrm{Fe}$ composite prepared by a warm compaction method were presented. Ball-milled Fe- 25 wt.\%Si powder, pure Fe powder and Si-polymer were mixed and then the powder mixture was compacted at various temperatures and pressures. Pore free density of samples up to $95 \%$ theoretical value has been obtained. The warm compacted sample prepared at $650 \mathrm{MPa}$ and $240^{\circ} \mathrm{C}$ had highest compaction properties in comparison with other compacts prepared at $300,400 \mathrm{MPa}$ and room temperature and $120^{\circ} \mathrm{C}$. The magnetic properties such as core loss, magnetization saturation and coercivity were measured by B-H curve analyzer and vibration sample magnetometer.
\end{abstract}

Keywords : Warm compaction, Magnetic property, Nanostructured powder, Powder core

\section{1. 서 론}

Fe-Si계 연자성 재료는 작은 와전류 손실을 가지며, 낮은 보자력과 높은 큐리온도의 특징을 가진 대표적 코어재료이다. 이는, $\mathrm{Fe}-\mathrm{Si}$ 합금의 실리콘이 자기 이 방성을 감소시키고 전기저항을 증가시킴으로써 보자 력과 와전류 손실을 감소시키기 때문인 것으로 보고 되고 있으며, 최근 연자성 부품의 성능향상에 대한 요구가 증가함에 따라 고 실리콘 함량, 절연재 개발, 신 공정 개발 등에 의한 자기적 특성향상에 대한 연 구들이 진행되고 있다[1-5].

일반적으로 $\mathrm{Fe}-\mathrm{Si}$ 합금에서 실리콘의 함량이 증가 할수록 재료의 취성이 매우 강해져 성형이 쉽지 않 으며, 분말코어 제조 시 에폭시와 같은 고분자 재료 를 절연체로 첨가하기 때문에 소결공정을 적용하기
어렵다. 이에 따른 해결법으로서 성형 후 안정도가 증가하고 후가공이 불필요하며 성형체의 고밀도화, 복잡한 형상의 고난도 가공화, 대형화 및 비용 절감 이 가능한 온간성형법을 적용하였다. 온간성형은 금 속의 온도상승에 따라 항복강도가 강하하는 특성을 이용하여 소성변형을 더욱 용이하게 함으로써 상온 에서의 일축성형에 비해 큰 밀도를 얻고 생산비용을 절감하는 효과가 있는 성형법으로 알려져 있다. 온간 성형 적용 시 고려할 변수로는 재료에 따른 성형온 도, 성형압력, 바인더 및 윤활제의 종류와 참가량의 결정 등이 있다. 이 중 바인더 및 윤활제는 온도에 따른 유동도를 고려하여 결정해야 한다[6,7].

본 연구에서는 중고주파에서 사용 가능한 분말 코 어를 제조함에 있어 고에너지 볼밀링을 통해 나노구 조를 가지는 $\mathrm{Fe}-25 \mathrm{wt} . \% \mathrm{Si}$ 합금을 제조한 후 성형성

*Corresponding Author : [Tel : +82-2-2220-0408; E-mail : ydkim1@hanyang.ac.kr] 
이 우수한 $\mathrm{Fe}$ 분말과 혼합하고 분말의 유동도 및 분 말간 접합성 향상을 통해 밀도 증가와 공극감소, 분 말간 절연을 위해 바인더 및 윤활제로서 폴리비닐 파 이롤리돈(polyvinyl pyrrolidone; PVP)을 첨가하여 온간성형을 실시하였다. 이때 성형체는 최종적으로 $\mathrm{Fe}-5 \mathrm{wt} . \% \mathrm{Si}$ 의 평균조성을 가지도록 혼합되었다. 또 한 최적의 온간성형 조건을 도출하기 위해 바인더 첨 가량, 성형 온도, 성형압력 등에 따른 성형밀도의 변 화에 대해 고찰하였으며, 제조된 성형체에 대한 자성 특성을 측정하였다.

\section{2. 실험방법}

본 연구에서는 가스분무법으로 제조된 평균입자 크
기가 $20 \mu \mathrm{m}$ 인 $\mathrm{Fe}-25 \mathrm{wt} \% \mathrm{Si}$ 합금분말(Hoeganaes Co., USA)과 평균입자 크기가 $3 \mu \mathrm{m}$ 인 $\mathrm{Fe}$ 분말 (BASF Co., Germany)을 원료분말로 사용하였다. $\mathrm{Fe}-\mathrm{Si}$ 합금분말의 경우 아르곤 분위기에서 용기에 밀 봉되어 $400 \mathrm{rpm}$ 의 회전속도로 20 시간 동안 고에너 지 볼밀링 과정을 수행하였다. 이때 볼과 분말의 장 입비는 10:1이었으며, 밀링 매체는 스테인리스스틸 볼 을 사용하였다. 그림 1 은 원료분말인 $\mathrm{Fe}$ 와 20 시간 볼 밀링한 $\mathrm{Fe}-\mathrm{Si}$ 합금분말의 주사전자현미경 관찰결과이 다. 원료분말인 $\mathrm{Fe}$ 분말과 볼밀링한 후의 $\mathrm{Fe}-\mathrm{Si}$ 합금분 말의 평균 입자 크기는 약 $3 \mu \mathrm{m}$ 이고, 특히 $\mathrm{Fe}-\mathrm{Si}$ 합 금분말의 경우 선행연구의 XRD, TEM 분석을 통해 그 평균 결정립 크기가 $16 \mathrm{~nm}$ 를 가지는 $\mathrm{fcc}_{-} \mathrm{Fe}_{3} \mathrm{Si}$ 와 $\mathrm{hcp}-\mathrm{Fe}_{5} \mathrm{Si}_{3}$ 상으로 이루어져 있음을 확인하였다[3]. 이러

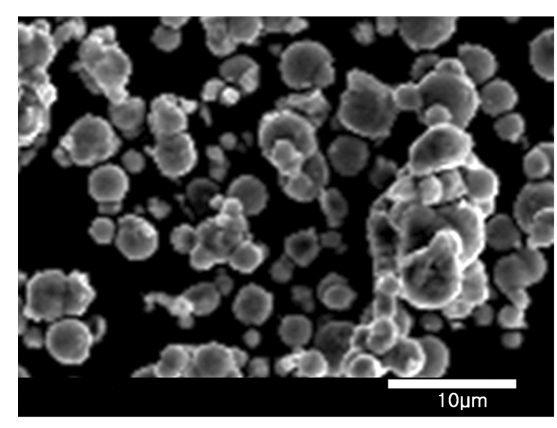

(a)

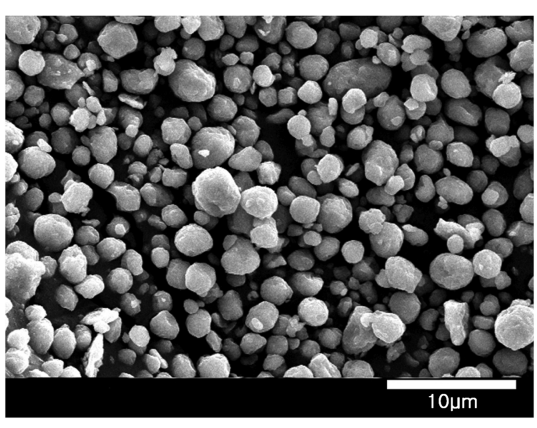

(b)

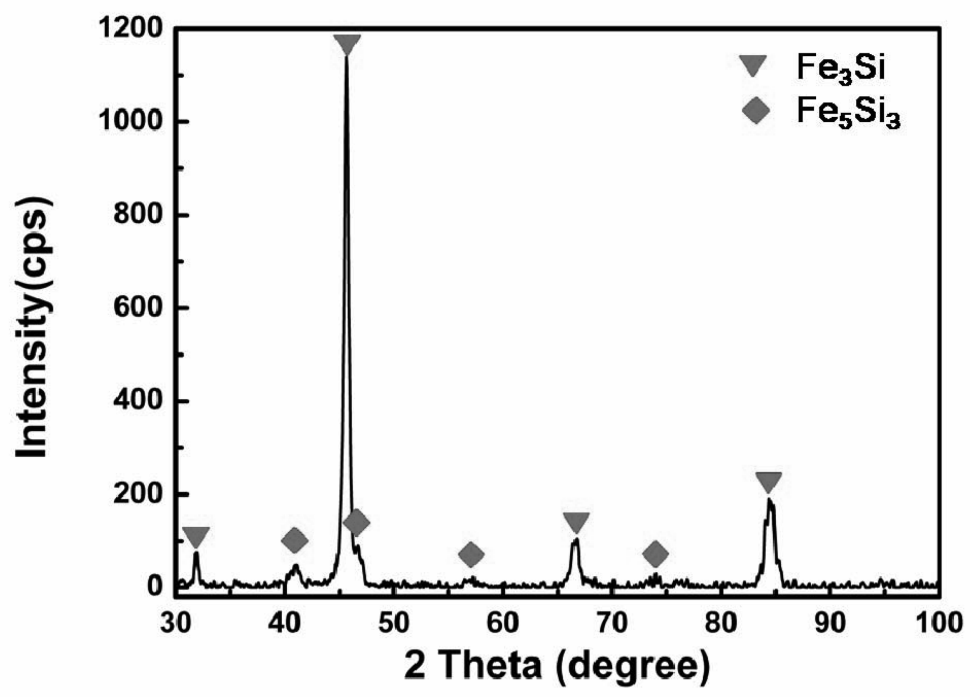

(c)

Fig. 1. Starting powders; (a) pure Fe powder, (b) ball-milled Fe-Si powder and (c) XRD pattern of ball-milled Fe-Si powder. 
한 볼밀링된 $\mathrm{Fe}-\mathrm{Si}$ 합금 분말과 $\mathrm{Fe}$ 분말에 $\mathrm{PVP}$ 를 첨가하여 3 차원 혼합기에서 1 시간 동안 혼합하여 온 간성형을 위한 혼합분말을 제조하였다. 혼합된 분말 은 온간성형기에서 최대 금형 온도 $240^{\circ} \mathrm{C}$, 최대 압 력 $650 \mathrm{MPa}$ 로 성형을 실시하였으며, 승온 후 30 분 간 유지시켜 분말과 금형의 온도를 같게 한 후 압력 을 가하고 30 분 동안 유지시켜 한 조건당 20 개의 시편을 제조하였다. 이때 금형벽 윤활제는 $\mathrm{Zn}$ stearate를 사용하였다. 이렇게 제조된 시편은 아르키 메데스법으로 그 밀도를 측정하였으며, 성형체내의 $\mathrm{Fe}-\mathrm{Si}$ 합금분말의 분포와 미세구조를 전자탐침 미세 분석기(EPMA)와 주사전자현미경(SEM)을 통해 분석 하였다. 또한 성형체의 자성특성은 상온에서 \pm 12.5 $\mathrm{kOe}$ 의 자장을 인가하여 진동시편자력계(VSM)를 이 용하여 측정하였다. 또한, $10 ~ 1000 \mathrm{kHz}$ 대역의 주파 수에서 성형체의 코어 손실을 측정하기 위하여 길이 $12 \mathrm{~mm}$, 지름 $10 \mathrm{~mm}$ 인 실린더 형태의 시편을 B-H curve 분석기와 임피던스 분석기를 사용하였다.

\section{3. 결과 및 고찰}

구형입자의 경우 입자의 변형을 수반하지 않고 충 전시켰을 때 이론적으로 $74 \%$ 까지 충전밀도를 얻을 수 있다. 불규칙형상을 갖는 입자의 경우 분말입자간 의 마찰력으로 밀도가 낮아지게 되며 분말 입자의 크 기가 작아질수록 낮아지는 경향을 나타낸다. 따라서 분말 입자의 성형에 있어서 $70 \%$ 이상의 성형밀도를 얻기 위해서는 입자의 소성변형이 수반되어야 한다. 그러나 본 연구에 사용된 $\mathrm{Fe}-25 \mathrm{wt} . \% \mathrm{Si}$ 의 경우 hcp$\mathrm{Fe}_{5} \mathrm{Si}_{3}$ 상과 같은 경한 상이 포함되어 있을 뿐만 아니 라 고에너지 볼밀링에 의한 나노구조를 가지고 있어 서 소성 변형이 어렵다.

이러한 성형특성을 가지는 $\mathrm{Fe}-\mathrm{Si}$ 합금분말의 분말 코어를 제조함에 있어 성형밀도를 향상시키기 위하 여 $\mathrm{Fe}$ 분말을 첨가하여 여러 조건에서 온간성형을 실 시하였다. 그림 2에 $\mathrm{Fe}-\mathrm{Si} / \mathrm{Fe}$ 혼합분말의 PVP 바인 더 유무에 따른 압력과 성형밀도의 관계를 나타내었 다. 그림에서 알 수 있듯이 압력의 증가에 따라서 성 형밀도는 직선적으로 증가하는 경향을 나타내고, PVP 를 첨가하였을 때 최대 $0.8 \mathrm{~g} / \mathrm{cm}^{3}$ 정도의 밀도 향상 이 이루어졌으며, 바인더 및 윤활제로 사용된 PVP가 매우 효과적으로 성형밀도 향상에 기여하였다. 그림

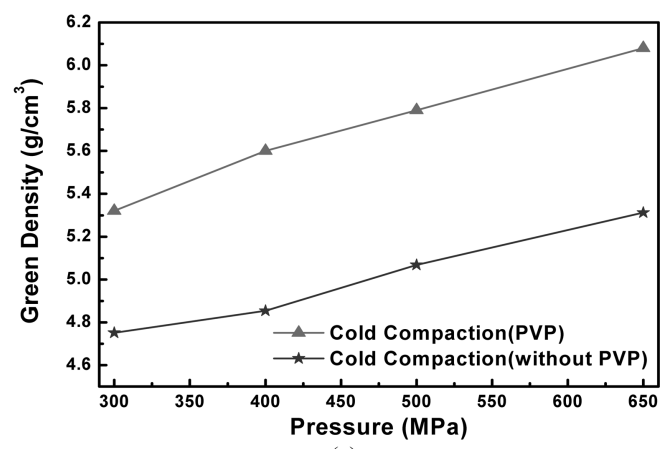

(a)

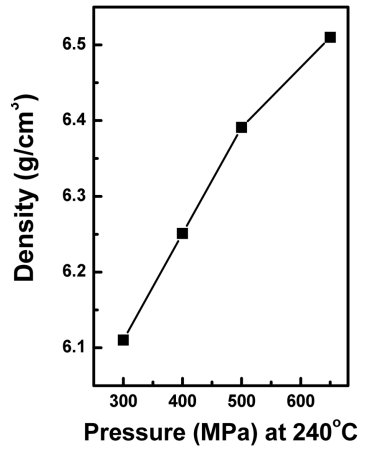

(b)

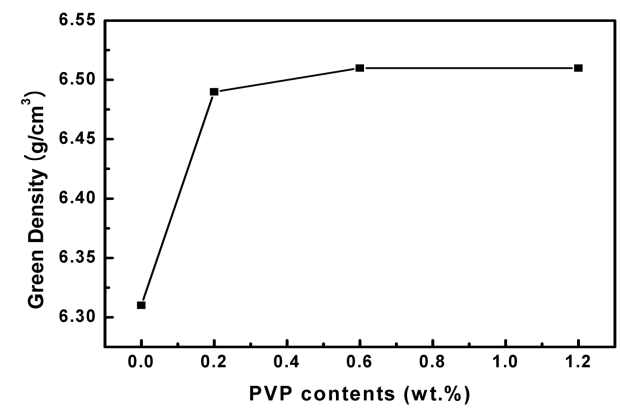

(d)

Fig. 2. The changes of densities for various compaction conditions.

2(b), (c)는 온간성형 조건에 따른 밀도변화 결과를 나타낸 것이다. PVP의 첨가량은 $0.6 \mathrm{wt} \%$ 였으며 (b) 의 경우 $240^{\circ} \mathrm{C}$ 의 성형온도에서 압력의 변화에 따른 밀도변화를 나타내었고 (c)는 $650 \mathrm{MPa}$ 의 압력에서 성형온도에 변화를 주어 온간성형을 실시한 결과이 다. 일축성형과 비교해 성형온도만 $240^{\circ} \mathrm{C}$ 로 변화를 주었을 때 $300 \mathrm{MPa}$ 의 압력에서 $5.3 \mathrm{~g} / \mathrm{cm}^{3}$ 에서 6.1 $\mathrm{g} / \mathrm{cm}^{3}$ 로 약 $0.8 \mathrm{~g} / \mathrm{cm}^{3}$ 의 밀도향상이 있었으며, 압력 이 증가할수록 밀도증가가 감소해 $650 \mathrm{MPa}$ 에서는 $6.1 \mathrm{~g} / \mathrm{cm}^{3}$ 에서 $6.5 \mathrm{~g} / \mathrm{cm}^{3}$ 로 $0.4 \mathrm{~g} / \mathrm{cm}^{3}$ 정도 밀도가 
향상되는 것을 확인할 수 있다. 이는 성형온도의 증 가가 재료의 항복점을 낮추어 보다 용이하게 소성변 형이 일어나도록 하여 밀도향상에 도움을 주는 온간 성형에 의한 것이다. 또한, 압력이 증가할수록 밀도 증가량이 감소하는 것은 $\mathrm{PVP}$ 의 밀도인 $1.2 \mathrm{~g} / \mathrm{cm}^{3}$ 를 고려하여 실제 PVP가 차지하고 있는 부피를 계산하 여 나타낸 밀도인 Pore free density (P.F.D)가 약 $5.3 \mathrm{~g} / \mathrm{cm}^{3}$ (상대밀도 $75 \%$ ) 이상일 때부터였다. 이러한 결과는 성형압력에 따른 분말의 소성변형이 나타나 기 시작하여 분말들 간의 접촉면적 증가에 의한 마 찰력 증가로 밀도증가량이 줄어들기 시작하기 때문 인 것으로 판단되며, 상대밀도로 $90 \%\left(6.3 \mathrm{~g} / \mathrm{cm}^{3}\right)$ 이 상의 밀도에서 폐기공이 형성되는 것 또한 밀도증가 율이 감소하는 한 요인인 것으로 판단된다. 성형압력 을 $650 \mathrm{MPa}$ 으로 고정하고 상온 $\left(20^{\circ} \mathrm{C}\right)$ 에서 $240^{\circ} \mathrm{C}$ 까 지 온도별로 온간성형을 실시한 결과인 그림 2(c)에 서 확인할 수 있듯이 성형온도가 증가할수록 밀도 증 가가 뚜렷하게 나타난다. 특히, $180^{\circ} \mathrm{C}$ 이상에서 성형 밀도가 $6.3 \mathrm{~g} / \mathrm{cm}^{3}$ 를 넘었음에도 불구하고 밀도의 증가 율이 증가되는 것이 확인되었는데 이는 온도에 따른 항복점 강하 효과와 더불어 바인더로 사용된 $\mathrm{PVP}$ 의 유리전이온도 $\left(\mathrm{T}_{\mathrm{g}}: 110 \sim 180^{\circ} \mathrm{C}\right)$ 이상으로 온간성형 온 도가 올라감에 따라 생기는 윤활효과에 의한 것으로 판단된다. 반면 $\mathrm{T}$ g이상의 온도에서 성형특성이 향상 되는 PVP의 함량에 따른 효과를 확인하기 위하여 $\mathrm{PVP}$ 함량을 변화시켜 $240^{\circ} \mathrm{C}, 650 \mathrm{MPa}$ 의 성형조건 으로 온간성형을 실시해 그림 2(d)에 나타내었다. $\mathrm{PVP}$ 를 전혀 첨가하지 않은 경우 $6.3 \mathrm{~g} / \mathrm{cm}^{3}$ 정도의 성형밀도였으나 $0.2 \mathrm{wt} . \%$ 첨가하였을 때 $6.5 \mathrm{~g} / \mathrm{cm}^{3}$ 로 약 $0.2 \mathrm{~g} / \mathrm{cm}^{3}$ 밀도 향상이 있었으며, $0.6 \mathrm{wt} . \%$ 이상 첨가된 경우는 거의 밀도향상이 일어나지 않음을 확 인할 수 있다. 상온에서 성형 시 PVP의 존재에 따 른 밀도증가량보다 이 경우의 증가량이 작음을 알 수 있으며, 이러한 결과는 온간성형 시 항복점 강하에 의한 소성변형의 효과가 밀도향상에 더 주도적인 역 할을 한다는 것을 뒷받침해준다.

온간성형으로 제조된 시편의 미세구조를 확인하기 위하여 EPMA 맵핑 분석을 실시하여 그림 3에 나타 내었다. $\mathrm{Fe}$ 와 $\mathrm{Si}$ 에 대한 맵핑 결과에서 볼 수 있듯 이 $\mathrm{Fe}-\mathrm{Si}$ 합금분말의 경우 온간성형에 의한 변형이 거의 없이 볼밀링한 후의 형태를 유지한 채로 분포 되어 있으며, $\mathrm{Fe}$ 분말의 경우 $\mathrm{Fe}-\mathrm{Si}$ 분말이 거의 구

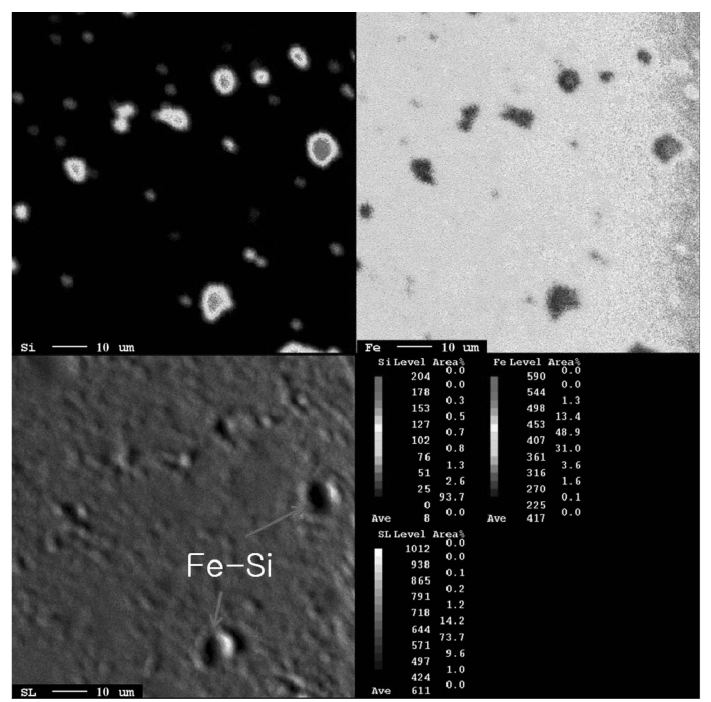

Fig. 3. EPMA mapping images of warm compacted sample.

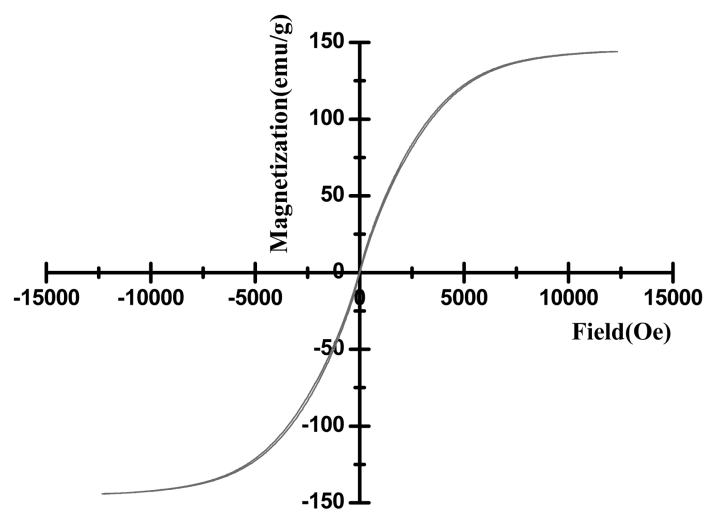

Fig. 4. Magnetic property of warm compacted Fe-5 wt.\%Si powder.

형을 유지하고 있는 것과는 다르게 초기 구형의 분 말형태가 발견되지 않고 분말간 계면이 거의 관찰되 지 않았다. 이는 $\mathrm{Fe}$ 분말의 소성변형이 온간성형체의 밀도 증가에 주도적인 역할을 했기 때문인 것으로 판 단된다.

그림 4는 PVP함량이 0.6 wt.\%인 $\mathrm{Fe}-\mathrm{Si} / \mathrm{Fe}$ 혼합분 말을 $240^{\circ} \mathrm{C}, 650 \mathrm{MPa}$ 의 조건으로 온간성형한 성형 체의 VSM 결과이다. $\mathrm{Fe}-25 \mathrm{wt} . \% \mathrm{Si}$ 분말의 경우 포 화자화 $\left(\mathrm{M}_{\mathrm{s}}\right)$ 값이 $58 \mathrm{emu} / \mathrm{g}$ 이고 $\mathrm{Fe}$ 분말은 189 $\mathrm{emu} / \mathrm{g}$ 인 분말이 사용되었는데, 평균조성이 $\mathrm{Fe}-$ $5 \mathrm{wt} . \% \mathrm{Si}$ 인 $\mathrm{Fe}-\mathrm{Si} / \mathrm{Fe}$ 혼합분말의 $\mathrm{M}$ 가 약 $144 \mathrm{emu} /$ $\mathrm{g}$ 으로 측정되어 $\mathrm{Fe}-5 \mathrm{wt} . \% \mathrm{Si}$ 합금분말의 $\mathrm{M}_{\mathrm{s}}$ 와 거의 


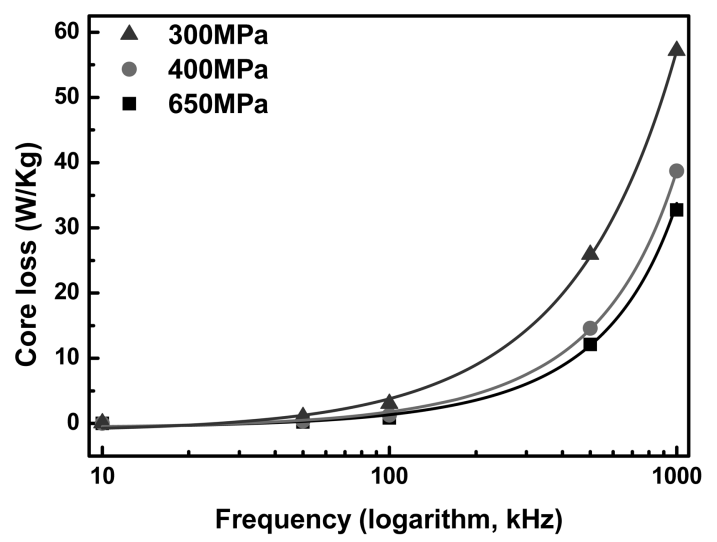

Fig. 5. Core losses of warm compacted $\mathrm{Fe}-5 \mathrm{wt}$ \% $\% \mathrm{Si}$ powder at $240^{\circ} \mathrm{C}$.

일치하는 경향을 보여주고 있다. 일반적으로 자성특 성이 다른 두 개의 상이 공존하는 경우 계단형태로 결과가 나타나게 되는데 측정된 VSM 결과는 하나의 상이 존재하는 것처럼 나타났다. 이러한 결과는 사용 된 $\mathrm{Fe}-\mathrm{Si}$ 분말과 $\mathrm{Fe}$ 분말이 $\mathrm{M}_{\mathrm{s}}$ 를 제외한 보자력 $\left(\mathrm{H}_{\mathrm{c}}\right)$ 과 투자율이 거의 같기 때문인 것으로 판단되며, $\mathrm{H}_{\mathrm{c}}$ 은 $11 \mathrm{Oe}$ 로 측정되었다.

그림 5는 $1 \mathrm{mT}$ 의 자장 하에서 $1000 \mathrm{kHz}$ 대역까 지의 주파수에서 성형압력에 따른 코어 손실을 측정 한 결과로 성형밀도가 높을수록 코어 손실이 작아지 는 것을 확인할 수 있다. 코어 손실의 경우 자기이력 손실, 와전류 손실, 잔류 손실의 합으로 나타낼 수 있으며, 이 중 와전류 손실은 포화자속밀도, 두께, 주 파수 등의 값에 비례하고 전기저항에는 반비례하는 관계를 가지며, 자기이력 손실은 결정자기이방성, 자 기변형, 포화자화 및 기공, 불순물, 결함 등의 양이 영향을 미친다고 알려져 있다. 특히, 성형밀도에 따 른 코어 손실 값에 차이가 나는 것으로 미루어 성형 압력 증가에 따른 잔류응력 증가가 자기이력 손실을 높이는 영향보다 성형밀도 증가에 따른 시편내부의 기공 감소가 자기이력 손실을 낮추는 효과가 더 지 배적으로 작용하여 성형밀도가 증가할수록 전체 코 어 손실이 감소하는 것으로 판단된다. 또한 $100 \mathrm{kHz}$ 이상의 주파수에서 코어 손실이 급격히 증가되는 현 상을 보여주는데 이러한 결과 역시 밀도가 증가할수 록 그 증가폭이 줄어드는 것으로 미루어 잔류 기공 에 의해 자기이력 손실이 증가하기 때문인 것으로 판 단된다. 따라서 적당한 양의 전기적 절연체 역할을
하는 바인더를 첨가하여 전기저항을 높여주고 성형 밀도를 높여 기공분율을 감소시키는 것으로 코어 손 실을 줄일 수 있을 것으로 판단된다.

\section{4. 결 론}

본 연구에서는 $\mathrm{Fe}-25 \mathrm{wt} . \% \mathrm{Si}$ 분말과 $\mathrm{Fe}$ 분말을 혼합한 후 온간성형을 하여 높은 밀도를 가지는 분 말 코어를 제조하고 그 자성특성을 측정하였으며 그 결과는 다음과 같다.

1. 성형성이 좋지 않은 볼밀링한 $\mathrm{Fe}-25 \mathrm{wt} . \% \mathrm{Si}$ 분 말과 상대적으로 성형성이 우수한 $\mathrm{Fe}$ 분말을 바인더 와 혼합하여 $240^{\circ} \mathrm{C}$ 의 온도에서 $650 \mathrm{MPa}$ 의 조건으로 온간성형한 결과 Pore Free Density(PFD)가 $95 \%$ 이상 인 $\mathrm{Fe}-5 \mathrm{wt} \% \mathrm{Si}$ 성형체를 제조할 수 있었다.

2. 온간성형을 통한 성형체의 밀도 향상은 $\mathrm{Fe}$ 분말 의 온도에 따른 항복점 강하 효과에 의한 것임을 확 인할 수 있었다. 또한, 온간성형 시 PVP 바인더의 $\mathrm{T}_{\mathrm{g}}$ 온도 이상에서 밀도 증가량이 증가되는 효과가 있 음이 확인되었다.

3. VSM 측정을 통해 $\mathrm{Fe}-\mathrm{Si} / \mathrm{Fe}$ 혼합분말 성형체가 같은 조성을 가지는 $\mathrm{Fe}-\mathrm{Si}$ 합금분말과 포화자화값이 $144 \mathrm{emu} / \mathrm{g}$ 으로 같은 자성특성을 가지는 것을 확인할 수 있었으며, $\mathrm{Fe}-\mathrm{Si} / \mathrm{Fe}$ 분말의 혼합비율에 따라 높은 실리콘 함량을 가지는 $\mathrm{Fe}-\mathrm{Si}$ 분말 코어를 제조할 수 있을 것으로 판단된다.

\section{참고문헌}

[1] B. Zuo, N. Saraswati, T. Sritharan and H. H. Hng: Materials Science and Engineering A, 371 (2004) 210.

[2] H. Shokrollahi and K. Janghorban: Materials Science and Engineering B, 134 (2006) 41.

[3] S. H. Kim, Y. J. Lee, B. H. Lee, K. H. Lee, K. Narasimhan and Y. D. Kim: Journal of Alloys and Compounds, 424 (2006) 204.

[4] I. Chicinas and O. Geoffroy: Journal of Magnetism and Magnetic Materials, 290-291 (2005) 1531.

[5] Y. G. Guo, J. G. Zhu and J. J. Zhong: Journal of Magnetism and Magnetic Materials, 302 (2006) 14.

[6] Y. Ozaki, S. Unami and S. Uenosono: Kawasaki Steel Technical Report, 47 (2002) 48.

[7] S. H. Kim, T. S. Jo, M. S. Park, Y. D. Kim: Journal of Korean Powder Metallurgy Institute, 14(3) (2007) 298 (Korean). 